\title{
Влияние примеси бора на излучательные свойства дислокационных структур в кремнии, сформированных путем имплантации ионов $\mathrm{Si}^{+}$
}

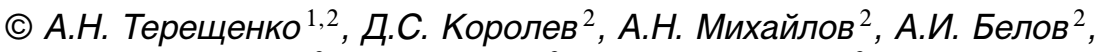 \\ А.А. Никольская ${ }^{2}$, Д.А. Павлов ${ }^{2}$, Д.И. Тетельбаум ${ }^{2}$, Э.А. Штейнман ${ }^{1}$ \\ ${ }^{1}$ Институт фризики твердого тела Российской академии наук, \\ 142432 Черноголовка, Россия \\ ${ }^{2}$ Нижегородский государственный университет им. Н.И. Лобачевского, \\ 603950 Нижний Новгород, Россия \\ E-mail: tan@issp.ac.ru
}

(Получена 31 октября 2017 г. Принята к печати 8 ноября 2017 г.)

Исследовано влияние имплантации бора на излучательные свойства дислокационных структур в кремнии, сформированных путем имплантации ионов $\mathrm{Si}^{+}$с последующим отжигом. Показано, что имплантация ионов $\mathrm{B}^{+}$существенным образом влияет как на интенсивность и состав спектра дислокационной люминесценции, так и на ход температурной зависимости интенсивности полосы D1. Обнаружено, что зависимость не является монотонной и имеет две области возрастания интенсивности полосы D1 с ростом температуры, образуя максимумы при 20 и $60-70 \mathrm{~K}$ на температурной зависимости. Максимум при $20 \mathrm{~K}$ связан с особенностями морфологии исследуемой дислокационной структуры, в то время как максимум при $60-70 \mathrm{~K}$ связан с дополнительной имплантацией примеси бора в дислокационную область образцов. Установлено, что интенсивности наблюдаемых максимумов, а также положение высокотемпературного максимума зависят от концентрации имплантированных ионов $\mathrm{B}^{+}$.

DOI: 10.21883/FTP.2018.07.46038.8759

\section{1. Введение}

Постоянное увеличение функциональности электронных схем приводит к соответствующему усложнению электрических схем. Это в свою очередь ставит задачу включения в электрическую схему оптико-волоконной связи. Учитывая, что значительная часть электроники основана на кремнии, оптическую часть тоже желательно реализовать на кремнии, что ставит задачу создания излучающих диодов, подходящих для оптической связи на кремниевых структурах. Использование кремния в качестве излучателя в ближней инфракрасной области спектра является одной из нерешенных проблем современной оптоэлектроники. Отчасти это связано с непрямой запрещенной зоной и соответственно малым квантовым выходом люминесценции в кремнии. Одним из эффективных решений этой проблемы является использование излучательной рекомбинации на глубоких энергетических состояниях, связанных с такими структурными дефектами в кремнии, как дислокации. Именно такой подход позволил получить один из лучших к настоящему времени результатов по внешнему квантовому выходу электролюминесценции в области 1.5мкм [1]. Наряду с широко применяемым методом пластической деформации центры дислокационной люминесценции (ДЛ) в кристаллах кремния могут быть созданы методом имплантации ионов кремния с последующей термообработкой [2-4]. Метод обладает целым рядом преимуществ, таких как технологичность и воспроизводимость, а также дает возможность контролируемого легирования с целью изменения дефектно-примесного состава. В то же время использование ДЛ ограничивается сильным температурным гашением интенсивности полосы D1 при 1.5 мкм, наиболее подходящей для практических целей.

Одним из способов существенного улучшения характеристик температурной зависимости ДЛ в области полосы D1 является уменьшение концентрации, а также электрической активности центров безызлучательной рекомбинации в кристалле, например, методами геттерирования и водородной пассивации [1]. Кроме того, недавно было показано $[5,6]$, что возможен и другой подход: при имплантации бора в дислокационные структуры наблюдается повышение интенсивности полосы D1, измеренной при $77 \mathrm{~K}$. Учитывая, что бор является одной из основных акцепторных примесей в кремнии и широко используется на практике для контролируемого легирования кремния, понимание влияния этой примеси на ДЛ представляется весьма важным как с фундаментальной, так и с практической точек зрения.

В данной работе приводятся результаты детального экспериментального исследования влияния облучения ионами бора с различными дозами на особенности спектров низкотемпературной дислокационной фотолюминесценции (ФЛ) в кремнии и на ее температурную зависимость.

\section{2. Методика эксперимента}

Для формирования дислокационных структур образцы кремния $n$-типа проводимости (марки КЭФ-4.5, (100)) были облучены на имплантере ИЛУ-200 ионами $\mathrm{Si}^{+}$ с энергией 100 кэВ и дозой $1 \cdot 10^{15} \mathrm{~cm}^{-2}$ в условиях, при которых повышение температуры за счет нагрева ионным пучком не превышало $10^{\circ} \mathrm{C}$. Данная доза 
обеспечивала аморфизацию кремния на глубинах до $\sim 200$ нм (в соответствии с данными обратного резерфордовского рассеяния) [4]. Затем образцы отжигались при $1100^{\circ} \mathrm{C}(1$ ч) в окислительной хлорсодержащей атмосфере (XСA) [6]. Приготовленные таким путем образцы подвергались облучению ионами $\mathrm{B}^{+}$с энергией 50 кэВ и с разными дозами, $1 \cdot 10^{15}, 3 \cdot 10^{15}, 1 \cdot 10^{16}$, $2 \cdot 10^{16}$ и $3 \cdot 10^{17} \mathrm{~cm}^{-2}$, с последующими изохронными (30 мин) отжигами при температурах $600,700,800^{\circ} \mathrm{C}$ в атмосфере осушенного азота. Поскольку после отжигов при $600^{\circ} \mathrm{C}$ и $\left(600^{\circ} \mathrm{C}-700^{\circ} \mathrm{C}\right)$ ФЛ отсутствовала, в дальнейшем приведены результаты только для образцов, прошедших все последовательные отжиги при 600,700 и $800^{\circ} \mathrm{C}$. Профиль распределения ионов $\mathrm{B}^{+}$после имплантации и отжига исследовался методом времяпролетной вторично-ионной масс-спектрометрии (ВИМС). Измерения ФЛ проводились в диапазоне температур $T=4.2-200 \mathrm{~K}$ по стандартной фазочувствительной методике с охлаждаемым германиевым фотосопротивлением в качестве детектора. ФЛ возбуждалась фотонами с длиной волны 920 нм при уровне оптического возбуждения $10 \mathrm{MBT} / \mathrm{MM}^{2}$, соответствующем линейному участку зависимости интенсивности ФЛ от мощности накачки. Структурные исследования образцов проводились методом просвечивающей электронной микроскопии (ПЭМ) поперечного сечения. Для этих целей был использован микроскоп JEM-2100F (JEOL), работающий при ускоряющем напряжении 200 кВ. Подготовка поперечного среза проводилась по стандартной технологии на оборудовании Gatan.

\section{3. Экспериментальные результаты и их обсуждение}

Структурные исследования образцов, идентичных образцам в настоящей работе, подробно проводились в работах $[5,6]$. Облучение образцов ионами $\mathrm{Si}^{+}$с энергией 100 кэВ и дозой $1 \cdot 10^{15} \mathrm{~cm}^{-2}$ с последующим отжигом при $1100^{\circ} \mathrm{C}(1$ ч) в ХCA приводит к генерации на глубинах до 800 нм 60-градусных и краевых дислокаций Ломера со средней плотностью $\sim 3 \cdot 10^{8} \mathrm{~cm}^{-2}$. Облучение ионами $\mathrm{B}^{+}$с последующими отжигами приводит к генерации на глубинах 100-500 нм большого количества дополнительных 60-градусных дислокаций и дислокаций Ломера с плоскостями скольжения (111) и (001) соответственно, в результате чего средняя плотность дислокаций возрастает более чем на порядок. Для примера на рис. 1, $a$ представлено ПЭМ-изображение поперечного среза образца Si с дислокационной структурой после облучения ионами $\mathrm{B}^{+} \mathrm{c}$ дозой $1 \cdot 10^{15} \mathrm{~cm}^{-2}$ и заключительного отжига при $800^{\circ} \mathrm{C}(30$ мин). На рис. $1, b$ представлен профиль распределения бора по глубине образца для указанных режимов имплантации и отжига. Режимы облучения ионами $\mathrm{B}^{+}$, использованные в данной работе, были подобраны так, чтобы максимум распределения акцепторов попадал в созданный ранее имплантацией кремния дислокационный слой.

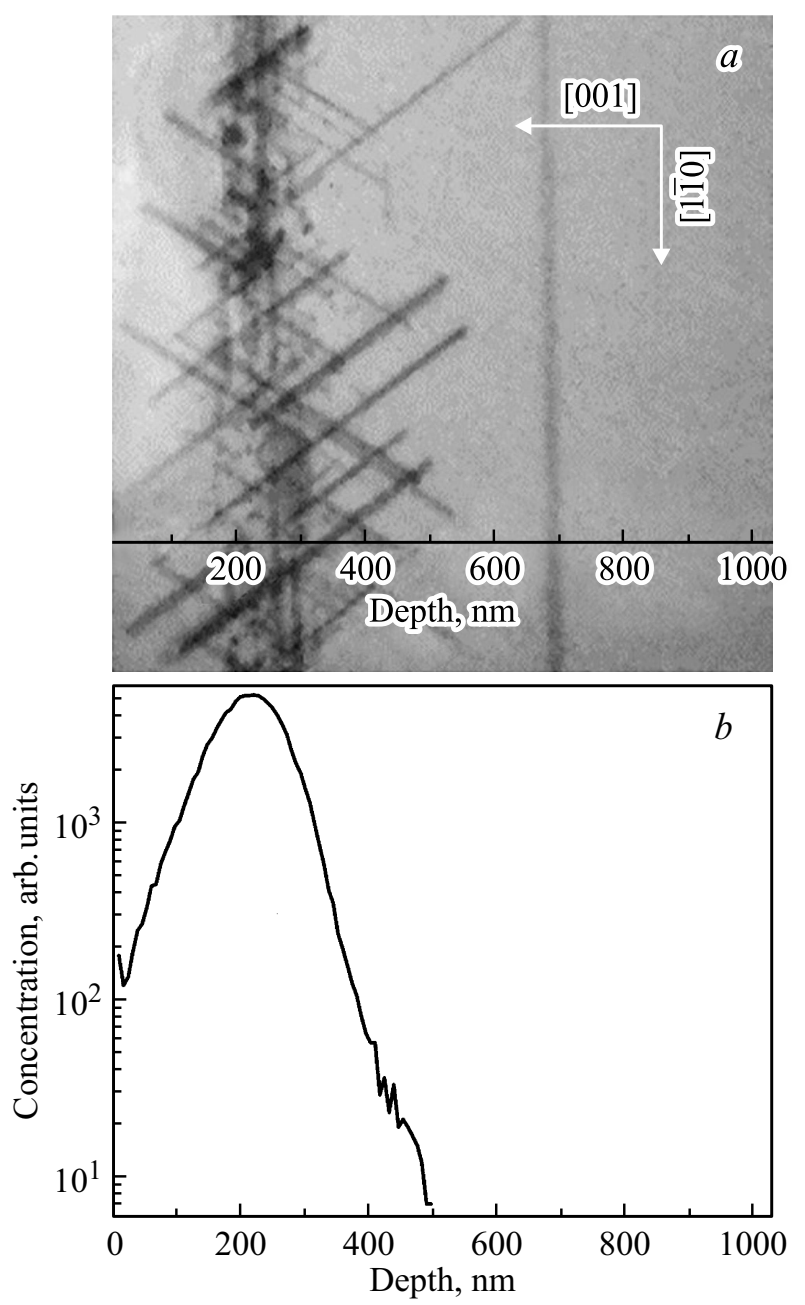

Рис. 1. $a-$ ПЭМ-изображение поперечного среза дислокационного слоя $\mathrm{Si}$ после имплантации бора $\left(1 \cdot 10^{15} \mathrm{~cm}^{-2}\right)$ и заключительного отжига при $800^{\circ} \mathrm{C}$ (30 мин); средняя плотность дислокаций $\sim 8 \cdot 10^{9} \mathrm{~cm}^{-2} . b-$ профиль распределения имплантированного бора по глубине дислокационного слоя.

На рис. 2 представлены спектры ФЛ образцов с созданной путем облучения ионами кремния и отжига в ХСА дислокационной структурой, спектр после дополнительного отжига при $800^{\circ} \mathrm{C}$, а также спектры образцов после имплантации ионов $\mathrm{B}^{+} \mathrm{c}$ дозами $1 \cdot 10^{15}$, $3 \cdot 10^{17} \mathrm{~cm}^{-2}$ и заключительного отжига при $800^{\circ} \mathrm{C}$.

Как известно, ДЛ в кремнии представляет собой серию полос D1-D4 в интервале энергий $0.8-1$ эВ [7]. Однако, как следует из рис. 2 , все приведенные спектры ФЛ имеют не полный набор полос ДЛ, а лишь полосы в длинноволновой части - D1 и D2. Во всех спектрах практически отсутствуют линия $\mathrm{D} 4(1.0$ эB) и ее фононное повторение D3 (0.934 эB). Так как линии D3 и D4 связаны с рекомбинацией носителей на прямолинейных участках расщепленных 60-градусных дислокаций [8-10], отсутствие в спектре данных линий люминесценции свидетельствует о соответствующей морфологии дислокаций, введенных методом имплантации ионов $\mathrm{Si}^{+}$ 


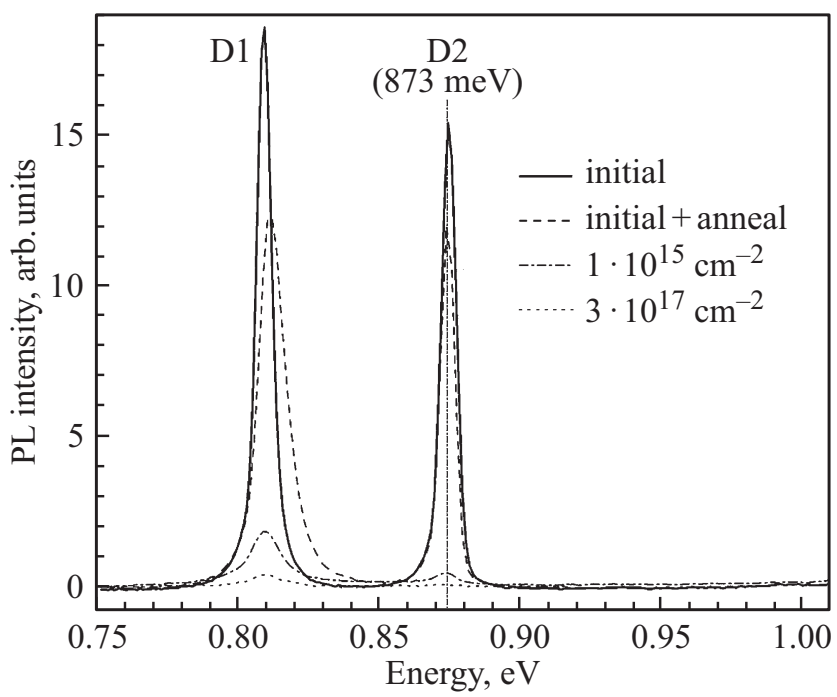

Pис. 2. Спектры фотолюминесценции (PL) при $6 \mathrm{~K}$ образцов с дислокациями, образованными путем имплантации $\mathrm{Si}^{+}$и последующего отжига при $1100^{\circ} \mathrm{C}$ : сразу после создания дислокационной структуры (до имплантации ионов $\mathrm{B}^{+}$); после серии дополнительных отжигов, но без имплантации бора; после имплантации ионами $\mathrm{B}^{+}$с различными дозами (указаны) и заключительного отжига при $800^{\circ} \mathrm{C}$.

в кремний. Отметим, что эта особенность (отсутствие в спектре ДЛ линий D3 и D4) присуща всем исследуемым в этой работе имплантированным образцам.

Серия дополнительных отжигов при $600,700,800^{\circ} \mathrm{C}$ (по 30 мин) образца, не облученного ионами $\mathrm{B}^{+}$, приводит к небольшому падению интенсивности всего спектра ДЛ и высокоэнергетическому сдвигу полосы D1, который можно связать с накоплением межузельного кислорода на дислокациях в процессе отжига [11].

Существенное гашение интенсивности всего спектра ДЛ происходит после имплантации ионов $\mathrm{B}^{+}$(рис. 2) даже при минимальной в нашем случае дозе $1 \cdot 10^{15} \mathrm{~cm}^{-2}$. При этом гашение линии D2 относительно линии D1 выражено сильнее. При повышении дозы имплантированного $\mathrm{B}^{+}$линия при 873 мэВ практически исчезает. Наблюдаемое гашение линий ДЛ связано главным образом с генерацией большого количества центров безызлучательной рекомбинации в процессе ионного легирования кремния. Кроме того, существенный вклад в гашение линии при 873 мэВ также вносит зависимость тонкой структуры полосы D2 от примесного состава кристалла Si. Как было показано ранее для пластически деформированных кристаллов $\mathrm{Si}$ [12], полоса D2 ДЛ имеет дублетную структуру с максимумами компонент при 869 и 873 мэВ. Такая структура полосы D2 наблюдается при уровне легирования кремния мелкими донорами или акцепторами $<10^{15} \mathrm{~cm}^{-3}$ и $<10^{16} \mathrm{~cm}^{-3}$ соответственно. Увеличение концентрации доноров приводит к гашению низкоэнергетической компоненты при 869 мэВ, в то время как увеличение концентрации акцепторов приводит к гашению высокоэнергетической компоненты при 873 мэВ полосы D2. Так как в работе используется кремний марки КЭФ-4.5 (концентрация фосфора $\sim 2 \cdot 10^{15} \mathrm{~cm}^{-3}$ ), то соответственно линия D2 изначально представлена только одной компонентой - 873 мэВ (рис. 2). При имплантации ионов $\mathrm{B}^{+}$даже с самой низкой использованной дозой происходит увеличение концентрации акцепторов в дислокационной области образцов заведомо $>10^{16} \mathrm{~cm}^{-3}$, что и приводит к гашению компоненты 873 мэВ линии D2. Источником же наблюдаемой очень слабой люминесценции в области 873 мэВ в некоторых имплантированных $\mathrm{B}^{+}$образцах являются дислокации из более глубоких слоев дислокационной структуры, где имплантированный бор отсутствует (что хорошо видно из рис. 1). Плотность таких дислокаций относительно мала, что и является причиной слабой интенсивности наблюдаемой компоненты.

Исследование спектров ДЛ при различных температуpax показало сильное влияние имплантации $\mathrm{B}^{+}$на спектральное распределение интенсивности люминесценции. Для примера на рис. 3 приведены спектры ДЛ при 6 и $80 \mathrm{~K}$ образца с исходной дислокационной структурой (до имплантации $\mathrm{B}^{+}$). Из сравнения этих спектров следует, что при повышении температуры происходит сдвиг полосы D1 в коротковолновую сторону, однако в соответствии с изменением ширины запрещенной зоны Si с ростом температуры (т.е. ее сужением) сдвиг люминесценции должен был произойти в противоположную (длинноволновую) сторону. Этот эффект (так называемый „синий сдвиг“) впервые наблюдался на пластически деформированных образцах кремния [13],

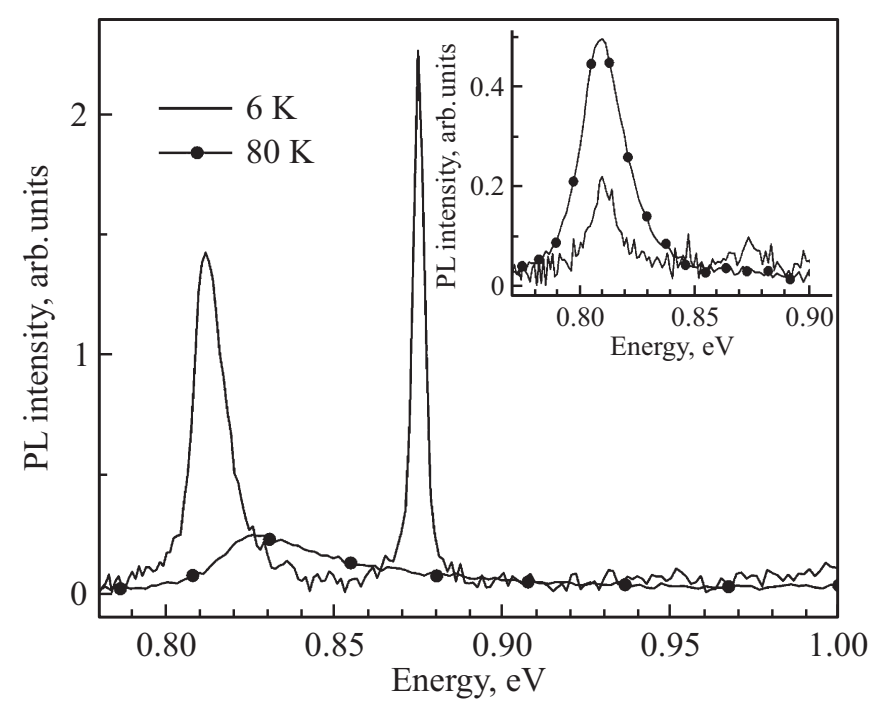

Рис. 3. Спектры дислокационной фотолюминесценции (PL) при температурах 6 и $80 \mathrm{~K}$ образца $\mathrm{Si}$ с исходной дислокационной структурой (до имплантации ионов $\mathrm{B}^{+}$). При повышении температуры от 6 до $80 \mathrm{~K}$ наблюдается сдвиг линии D1 в коротковолновую область. На вставке - спектры ДЛ при температурах 6 и $80 \mathrm{~K}$ образца, дополнительно имплантированного ионами $\mathrm{B}^{+}$с дозой $1 \cdot 10^{16} \mathrm{~cm}^{-2}$, сдвига линии D1 в коротковолновую область не наблюдается. 
а позже и на имплантированных ионами $\mathrm{Si}^{+}$образцах $[3,4]$. В работе [13] при концентрации доноров в кристалле > $10^{15} \mathrm{~cm}^{-3}$ наблюдался высокоэнергетический сдвиг полос D1/D2 при повышении температуры, что связывалось с эффектом экранирования дислокаций свободными электронами. В то же время, как видно из вставки к рис. 3, в имплантированных $\mathrm{B}^{+}$образцах этого эффекта не наблюдается. Этот результат можно объяснить тем, что при имплантации в исследуемые структуры ионов $\mathrm{B}^{+}$в имплантированной области тип проводимости меняется с электронного на дырочный. Таким образом, во всех образцах, облученных бором, исследуется люминесценция из области $p$-типа проводимости, где высокоэнергетического сдвига, согласно [13], наблюдаться не должно. Кроме того, энергетическая структура легированных бором образцов тоже может быть иной, чем в нелегированных образцах [14].

Весьма неожиданным оказалось поведение интенсивности линии D1 при повышении температуры. Как видно из рис. 3, в образце с исходной дислокационной структурой интенсивность люминесценции падает с ростом температуры, в то время как в имплантированном бором образце люминесценция при $80 \mathrm{~K}$ оказалась выше, чем при $6 \mathrm{~K}$ (см. вставку к рис. 3). Рассмотрим подробнее температурные зависимости интенсивности линии D1 для образцов с различным содержанием бора (рис. 4). Первой особенностью этих зависимостей является рост интенсивности линии D1 в диапазоне 6-20 K. Такое поведение ДЛ характерно для всех исследуемых образцов: как с различным содержанием бора, так и не легированных бором. Как видно из рис. 4, во всех случаях данный низкотемпературный максимум находится примерно в одном положении (около $20 \mathrm{~K}$ ) и его амплитуда возрастает с увеличением дозы имплантированного бора.

Ярко выраженные различия в температурной зависимости для легированных и не легированных бором образцов наблюдаются при температурах > $20 \mathrm{~K}$. В то время как люминесценция образцов без бора при температурах выше $20 \mathrm{~K}$ испытывает характерное для ДЛ монотонное гашение, температурная зависимость в имплантированных бором образцах имеет качественно иной вид. При имплантации $\mathrm{B}^{+} \mathrm{c}$ дозами $1 \cdot 10^{15}$ и $3 \cdot 10^{15} \mathrm{~cm}^{-2}$ имеет место существенно меньшая скорость гашения люминесценции после $40 \mathrm{~K}$, чем в нелегированных образцах, и с увеличением концентрации бора эта тенденция усиливается. В дополнение к этому при дозах бора $1 \cdot 10^{16}$ и $2 \cdot 10^{16} \mathrm{~cm}^{-2}$ на температурной зависимости появляется второй максимум в области $60-70 \mathrm{~K}$, интенсивность и положение которого зависят от дозы имплантированного бора. Наибольшая интенсивность данного максимума достигается при дозе бора $2 \cdot 10^{16} \mathrm{~cm}^{-2}$. Увеличение дозы $\mathrm{B}^{+}$до $3 \cdot 10^{17} \mathrm{~cm}^{-2}$ сохраняет качественный вид температурной кривой, но приводит к увеличению скорости гашения полосы D1 с ростом температуры и практически к полному исчезновению высокотемпературного максимума.

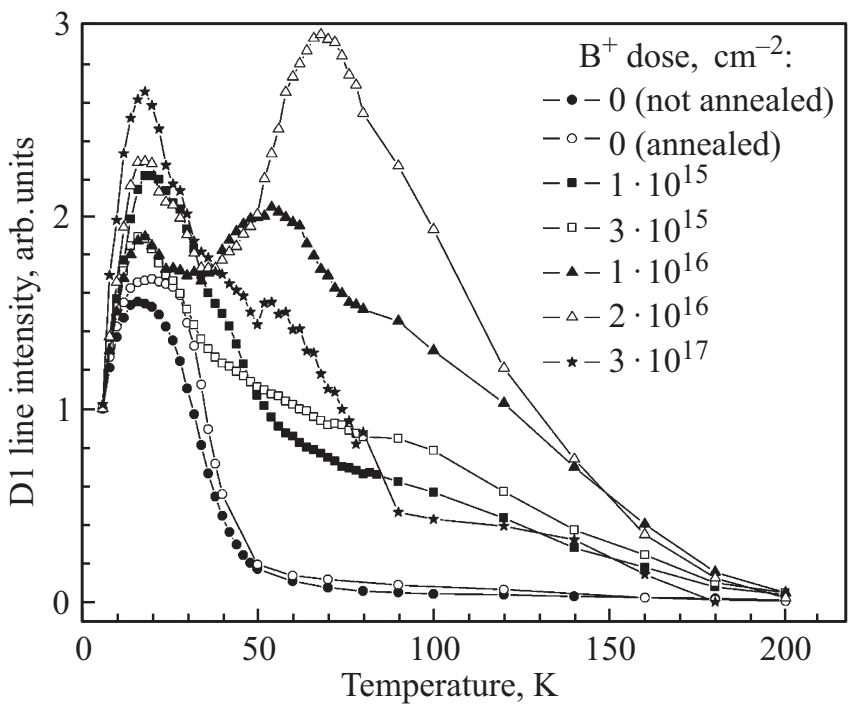

Рис. 4. Зависимости интенсивности полосы D1 от температуры (кривые нормированы) для образцов, облученных ионами бора с различными дозами и прошедших серию изохронных отжигов, а также для образца без облучения ионами $\mathrm{B}^{+}$и отжигов и образца без облучения, но после серии изохронных отжигов.

Рассмотрим возможные механизмы наблюдаемого температурного поведения люминесценции исследуемых образцов. Как было отмечено выше, сам факт увеличения интенсивности полосы D1 в диапазоне температур $6-20 \mathrm{~K}$ не зависит от наличия бора в образце и связан, по-видимому, с особенностями излучательной рекомбинации в исследуемых дислокационных структурах. Аналогичное поведение температурной зависимости при низких температурах наблюдалось ранее в дислокационных структурах, полученных на границе сращённых разориентированных кремниевых пластин [15]. В этом случае дислокационные структуры также представляли собой тонкий слой с высокой плотностью дислокаций (сравнимой с плотностью в данных образцах). Столь большая плотность дислокаций $\left(10^{9}-10^{10} \mathrm{~cm}^{-2}\right)$ обеспечивает высокую концентрацию центров излучения D1, что приводит к возникновению конкуренции глубоких (D1) и различных мелких центров в захвате экситонов. При увеличении температуры начинается интенсивный выброс экситонов с мелких центров и увеличивается вероятность их захвата на более глубокие центры D1, что приводит к росту интенсивности соответствующей люминесценции. Кроме того, с увеличением дозы имплантированного бора вследствие легирования и смещения уровня Ферми происходит сглаживание потенциального рельефа для компонентов экситона (электрона и дырки), что облегчает их захват на центры D1. Таким образом, можно ожидать увеличения вероятности захвата носителей на эти центры (и соответственно более интенсивной люминесценции D1) в образцах с более высоким содержанием имплантированного бора. 
Как видно из рис. 4, величина пика при $20 \mathrm{~K}$ действительно возрастает с увеличением дозы имплантированного бора. При температурах $>20 \mathrm{~K}$ интенсивность люминесценции начинает падать с энергией активации гашения $\sim 12$ мэВ, близкой к энергии связи свободных экситонов [16].

Появление второго максимума на температурной зависимости однозначно связано с дополнительной имплантацией примеси бора в образцы, причем наблюдается корреляция зависимостей интенсивности и положения данного максимума от дозы имплантированного бора. Известно, что при ионной имплантации происходит генерация множества дефектов кристаллической решетки, которые при последующем отжиге частично отжигаются или образуют различные комплексы. В нашем случае образцы подвергались двойной имплантации (сначала $\mathrm{Si}^{+}$, затем $\mathrm{B}^{+}$) и последующим отжигам, в связи с чем мы гарантированно имеем ряд кластеров и комплексов, в том числе включающих бор, - например, комплексы бора с собственными межузельными атомами, преципитаты бора и т. П. [17,18]. При этом часть комплексов может быть электрически активной и способной захватывать на свои уровни избыточные носители заряда. Тогда наблюдаемые пики на температурной зависимости можно связать с термическим высвобождением захваченных носителей с этих ловушек и их перекачкой на центры D1. C ростом дозы имплантированного бора мы имеем как рост числа ловушек, так и увеличение концентрации D1-центров, вследствие чего происходит более эффективная подкачка центров люминесценции в таких образцах. Однако с ростом дозы имплантированного бора происходит также увеличение концентрации различных дефектов в кристалле и, как следствие, рост концентрации центров безызлучательной рекомбинации. С ростом температуры увеличивается вероятность захвата носителей на эти центры, что приводит к более интенсивному гашению люминесценции в таких образцах. Действительно, на рис. 4 из наклона температурных зависимостей на участке 80-200 K отчетливо видно, как увеличивается скорость гашения интенсивности линии D1 с температурой при увеличении дозы имплантированного бора в образце. При максимальной для исследуемых образцов дозе $\mathrm{B}^{+}\left(3 \cdot 10^{17} \mathrm{~cm}^{-2}\right)$ практически исчезает высокотемпературный максимум на температурной зависимости. Такое поведение интенсивности люминесценции связано с очень высокой концентрацией эффективных центров безызлучательной рекомбинации, частью которых могут быть преципитаты бора, интенсивно образующиеся при таких концентрациях $\mathrm{B}^{+}[19]$. В заключение заметим, что усложнение системы энергетических уровней в имплантированных бором образцах, возникновение и рост концентрации центров излучательной и безызлучательной рекомбинации требуют построения количественной модели для расчета температурной зависимости ДЛ, что является отдельной задачей.

\section{4. Заключение}

Таким образом, в данной работе проведено экспериментальное исследование влияния имплантации ионов бора на излучательные свойства дислокационных структур в кремнии, сформированных путем имплантации ионов $\mathrm{Si}^{+}$с последующим отжигом. Изучены особенности спектров низкотемпературной фотолюминесценции таких структур, а также их температурные зависимости. Установлено, что имплантация ионов $\mathrm{B}^{+} \mathrm{c}$ последующей термообработкой приводит к появлению дополнительного максимума на температурной зависимости, интенсивность и положение которого зависят от концентрации имплантируемого $\mathrm{B}^{+}$. Предполагается, что возникновение данного максимума связано с термическим высвобождением носителей из дефектнопримесных комплексов, что приводит к эффективному увеличению накачки D1-центров люминесценции.

Авторы выражают благодарность Н.А. Соболеву и Е.И. Шек за отжиг образцов в хлорсодержащей атмосфере и участие в обсуждении результатов. Работа выполнена при частичной поддержке Российского фонда фундаментальных исследований (гранты № 17-02-01070 и 16-32-50184), а также частично при поддержке Министерства образования и науки России в рамках государственного задания (№ 16.2737.2017/4.6). Д.С. Королев благодарит за поддержку Совет по грантам Президента РФ (стипендия Сп-1147.2018.3).

\section{Список литературы}

[1] V. Kveder, M. Badylevich, E. Steinman, A. Izotov, M. Zeibt, W. Schröter. Appl. Phys. Lett., 84, 2106 (2004).

[2] Н.А. Соболев, А.М. Емельянов, В.И. Сахаров, И.Т. Серенков, Е.И. Шек, Д.И. Тетельбаум. ФТП, 41 (5), 555 (2007).

[3] Н.А. Соболев, А.Е. Калядин, М.В. Коновалов, П.Н. Аруев, В.В. Забродский, Е.И. Шек, К.Ф. Штельмах, А.Н. Михайлов, Д.И. Тетельбаум. ФТП, 50 (2), 241 (2016).

[4] Н.А. Соболев, А.Е. Калядин, Р.Н. Кютт, В.И. Сахаров, И.Т. Серенков, Е.И. Шек, В.В. Афросимов, Д.И. Тетельбаум. ФТП, 45 (9), 1182 (2011).

[5] D.I. Tetelbaum, A.N. Mikhaylov, A.I. Belov, D.S. Korolev, A.N. Shushunov, A.I. Bobrov, D.A. Pavlov, E.I. Shek, N.A. Sobolev. Phys. Status Solidi C, 12 (1-2), 84 (2015).

[6] А.Н. Михайлов, А.И. Белов, Д.С. Королев, А.О. Тимофеева, В.К. Васильев, А.Н. Шушунов, А.И. Бобров, Д.А. Павлов, Д.И. Тетельбаум, Е.И. Шек. ФТП, 48 (2), 212 (2014).

[7] Н.А. Дроздов, А.А. Патрин, В.Д. Ткачев. Письма ЖЭТФ, 23 (11), 651 (1976).

[8] E.A. Steinman, V.I. Vdovin, T.G. Yugova, V.S. Avrutin, N.F. Izyumskaya. Semicond. Sci. Technol., 14, 582 (1999).

[9] R. Sauer, Ch. Kisielowski-Kemmerich, H. Alexander. Phys. Rev. Lett., 57, 1472 (1986).

[10] A.N. Izotov, A.I. Kolyubakin, S.A. Shevchenko, E.A. Steinman. Phys. Status Solidi A, 130, 193 (1992).

[11] E.A. Steinman. Phys. Status Solidi C, 2 (6), 1837 (2005). 
[12] E.A. Steinman, A.N. Tereshchenko, V.I. Orlov, F. Kirscht. Sol. St. Phenomena, 108-109, 767 (2005).

[13] E.A. Steinman, A.N. Tereshchenko, N.V. Abrosimov. Sol. St. Phenomena, 131-133, 607 (2008).

[14] S.N. Nagornykh, V.I. Pavlenkov, D.I. Tetelbaum, A.N. Mikhaylov, A.I. Belov, D.S. Korolev, A.N. Shushunov, A.I. Bobrov, D.A. Pavlov, E.I. Shek. Modern Electronic Mater., 1 (2), 33 (2015).

[15] E.A. Steinman, O. Kononchuk, A.N. Tereshchenko, A.A. Mazilkin. Sol. St. Phenomena, 156-158, 555 (2010).

[16] K.L. Shaklee, R.E. Nahory. Phys. Rev. Lett., 24, 942 (1970).

[17] J. Adey, J.P. Goss, R. Jones, P.R. Briddon. Physica B, 340-342, 505 (2003).

[18] J. Adey, J.P. Goss, R. Jones, P.R. Briddon. Phys. Rev. B, 67, 245325 (2003).

[19] К.В. Феклистов, Л.И. Федина, А.Г. Черков. ФТП, 44 (3), 302 (2010).

Редактор Л.В. Шаронова

\section{Influence of boron impurity on the emitting properties of dislocation structures in silicon formed by $\mathrm{Si}^{+}$ion implantation}

A.N. Tereshchenko ${ }^{1,2}$, D.S. Korolev ${ }^{2}$, A.N. Mikhaylov ${ }^{2}$, A.I. Belov ${ }^{2}$, A.A. Nikolskaya ${ }^{2}$, D.A. Pavlov ${ }^{2}$, D.I. Tetelbaum ${ }^{2}$, E.A. Steinman ${ }^{1}$

${ }^{1}$ Institute of Solid State Physics, Russian Academy of Sciences, 142432 Chernogolovka, Russia

${ }^{2}$ Lobachevsky State University of Nizhny Novgorod, 603950 Nizhny Novgorod, Russia

Abstract The influence of boron implantation on the emitting properties of dislocation structures in silicon formed by $\mathrm{Si}^{+}$ion implantation with subsequent annealing was studied. It is shown that $\mathrm{B}^{+}$ion implantation significantly influences on both the intensity and composition of a dislocation luminescence spectrum and on the temperature dependence of the D1 band intensity. It is discovered that the dependence is not monotonic, demonstrates two regions of D1 band intensity increase with temperature increasing, at that forming intensive maxima at 20 and $60-70 \mathrm{~K}$ of the temperature dependence. It is shown that the maximum at $20 \mathrm{~K}$ is related to the morphology peculiarities of the dislocation structure under study, while the maximum at $60-70 \mathrm{~K}$ is related to the additional implantation of boron impurity into the dislocation region of the samples. It is determined that the intensities of the maxima observed, as well as the position of high-temperature maximum, depend on the concentration of implanted $\mathrm{B}^{+}$ions. 